\title{
Medical and Surgical Management of Pediatric Ulcerative Colitis
}

\author{
José M. Cabrera, MD ${ }^{1}$ Thomas T. Sato, MD, FACS, FAAP²
}

\author{
${ }^{1}$ Division of Pediatric Gastroenterology, Department of Pediatrics, \\ Children's Hospital of Wisconsin, Medical College of Wisconsin, \\ Milwaukee, Wisconsin \\ 2 Division of Pediatric Surgery, Department of Surgery, Children's \\ Hospital of Wisconsin, Medical College of Wisconsin, Children's \\ Corporate Center, Milwaukee, Wisconsin
}

\begin{abstract}
Address for correspondence Thomas T. Sato, MD, FACS, FAAP, Division of Pediatric Surgery, Department of Surgery, Children's Hospital of Wisconsin, Medical College of Wisconsin, Children's Corporate Center, Suite C320, 999 North 92nd Street, Milwaukee, WI 53226 (e-mail: ttsato@chw.org).
\end{abstract}

\author{
Abstract \\ Keywords \\ - pediatric \\ - colitis \\ - ulcerative colitis \\ - inflammatory bowel \\ disease
}

Inflammatory bowel disease (IBD) describes a spectrum of idiopathic, lifelong, and progressive intestinal inflammatory conditions that includes Crohn's disease, ulcerative colitis, and indeterminate colitis. A worldwide increase in the incidence of IBD has been observed. In comparison to adults, IBD occurring during childhood and adolescence has several unique clinical characteristics and surgical management issues. In this article, we provide an overview contrasting these important differences.
Inflammatory bowel disease (IBD) describes a spectrum of idiopathic, lifelong, and progressive intestinal inflammatory conditions that includes Crohn's disease, ulcerative colitis (UC), and indeterminate colitis. A worldwide increase in the incidence of IBD has been observed. There is clear geographic distribution, with highest prevalence rates in North America, Northern Europe, and Australia and lower prevalence in South America. Emerging evidence is consistent with the hypothesis that genetic and environmental factors have significant impact on disease onset, phenotype, and clinical course. In comparison to adults, IBD occurring during childhood and adolescence has several unique clinical characteristics and surgical management issues.

Pediatric IBD is relatively uncommon, with an incidence rate about one-half of the rate for childhood leukemia. Therefore, optimal management in a multidisciplinary center with clinical volume, diagnostic, and treatment expertise in pediatric IBD is highly desirable. Statewide, prospective populationbased studies in Wisconsin demonstrated an overall pediatric IBD incidence rate of 9.5 per 100,000; the incidence of Crohn's disease was 6.6 per 100,000 and of UC was 2.4 per $100,000{ }^{1,2}$ This incidence is similar to rates found in administrative and medical record database reviews from Ontario, Canada, and Northern California. ${ }^{3,4}$ In the Wisconsin cohort, there was equal disease distribution across racial groups and no effect of rural versus urban environment on disease incidence. A positive family history with a first- or second-degree relative with IBD was present in $21 \%$ of all newly diagnosed children. The average age of onset of symptoms of UC was 12.5 years, and $21 \%$ had extraintestinal manifestations. Pancolitis was present in $66 \%$ at the time of diagnosis, with $13 \%$ requiring operation within 4 years. Multivariate data analysis from a large, multicenter pediatric IBD database identified serum albumin less than $3.5 \mathrm{~g} / \mathrm{dL}$, significant weight loss at the time of diagnosis, and a first-degree relative with UC as predictive of the need for earlier colectomy. ${ }^{5}$

\section{Differences in Presentation in the Pediatric Patient}

Ulcerative colitis is a chronic inflammatory disease affecting the mucosa of the colon. The hallmark symptoms of children with UC include rectal bleeding, diarrhea, and abdominal pain. Children with UC may present with several different patterns of symptoms based on the extent and severity of mucosal and systemic inflammation associated with their disease. ${ }^{6}$

Most children with UC present with early diarrhea with rectal bleeding and may have no systemic signs. For these "less inflamed" children, there is usually no abdominal tenderness on physical examination. Approximately one-third of children
Issue Theme Pediatric and Congenital Colorectal Diseases in the Adult Patient; Guest Editor: David M. Gourlay, MD, FACS, FAAP
Copyright (c) 2018 by Thieme Medical Publishers, Inc., 333 Seventh Avenue, New York, NY 10001, USA. Tel: +1(212) 584-4662.
DOI https://doi.org/ 10.1055/s-0037-1609021. ISSN 1531-0043. 
present with signs of greater systemic inflammation. These "more inflamed" patients present with bloody diarrhea, cramping with urgency to defecate, fatigue, fevers, poor appetite with weight loss, anemia, and hypoalbuminemia. In these cases, there is abdominal tenderness on physical examination, and stool testing can reveal variable amounts of blood and leukocytes. ${ }^{7,8}$

Up to $10 \%$ of children present with severe colitis distinguished by five or more bloody stools daily, marked anemia, hypoalbuminemia, weight loss, fever, and tachycardia. Physical examination can reveal diffuse tenderness or distension. Children with this severe presentation are less likely to respond to medical management and may require early surgical therapy. ${ }^{9}$ Presentation with isolated proctitis is uncommon in children but can be characterized by tenesmus, urgency, and bloody/ mucoid stools. ${ }^{10}$ One-third to half of children presenting with limited distal proctitis or proctosigmoiditis can progress to more extensive colitis. ${ }^{11-14}$

Although UC is primarily defined by signs and symptoms of colitis, children with UC may also show signs of gastroesophageal reflux or dyspepsia, with concurrent mucosal changes of the upper gastrointestinal tract. ${ }^{15,16} \mathrm{~A}$ controlled, blinded endoscopic study of children with UC found significant rates of esophagitis (50\%), gastritis (69\%), and duodenitis (23\%) in a studied cohort of UC patients. ${ }^{15}$ The nature of these upper gastrointestinal mucosal findings in children with UC remains unclear. In 25 to $33 \%$ of patients, the gastrointestinal symptoms of UC are preceded by extraintestinal manifestations of disease (-Table 1). ${ }^{17-19}$ The initial indication of UC may also be growth failure characterized by decreased linear growth velocity. ${ }^{20,21}$

Children with UC may experience several serious complications. In adults, toxic megacolon is a life-threatening complication of UC characterized by total or segmental nonobstructive dilatation of the colon of at least $6 \mathrm{~cm}$ in transverse diameter associated with marked clinical decline including fever, and abdominal tenderness with or without peritoneal signs. ${ }^{22-24}$ Other clinical signs of toxic megacolon include tachycardia, leukocytosis, hypokalemia, hypomagnesaemia, hypoalbuminemia, dehydration, hypotension, and mental status changes. ${ }^{22,24}$ The effect of steroid therapy may blunt the overt clinical signs of toxic megacolon. Children with toxic megacolon are at risk of colonic perforation, gram-negative sepsis, and severe bleeding. ${ }^{22}$ Toxic megacolon is uncommon in children with UC, and the overall incidence of toxic megacolon may be decreasing due to earlier recognition and improved treatment of severe colitis. ${ }^{24}$ In patients with suspected toxic megacolon, diagnostic procedures that can cause colonic distention (colonoscopy and barium enema) may compromise colonic blood flow and increase mucosal permeability to bacteria. ${ }^{24}$ Early discontinuation or rapid tapering of steroids or aminosalicylates has been associated with the development of toxic megacolon. ${ }^{24,25}$ Other risk factors for toxic megacolon include drugs that decrease colonic motility, such as anticholinergics, narcotics, and antidepressants with anticholinergic properties. ${ }^{25-27}$

Ideal management for toxic megacolon includes early surgical consultation, stool studies for bacterial pathogens and Clostridium difficile, establishment of physiological homeostasis, and initiation of broad-spectrum antibiotics
Table 1 Extraintestinal manifestation of ulcerative colitis

\begin{tabular}{|c|c|}
\hline \multirow[t]{5}{*}{ Hepatobiliary } & Sclerosing cholangitis \\
\hline & Cholelithiasis \\
\hline & Autoimmune hepatitis \\
\hline & Fatty liver disease $\mathrm{a}^{\mathrm{a}}$ \\
\hline & Elevated liver enzymes \\
\hline \multirow[t]{6}{*}{ Musculoskeletal } & Peripheral arthopathy \\
\hline & Osteopenia, osteoporosis ${ }^{\mathrm{a}}$ \\
\hline & Hypertrophic osteoarthropathy \\
\hline & Enthesopathy \\
\hline & Ankylosing spondylitis/sacroiliitis \\
\hline & $\begin{array}{l}\text { Osteonecrosis (avascular/aseptic } \\
\text { necrosis of the bone or } \\
\text { osteochondritis dissecans) }^{a}\end{array}$ \\
\hline \multirow[t]{5}{*}{ Skin } & Pyoderma gangrenosum \\
\hline & Erythema nodosum \\
\hline & Acne $^{a}$ \\
\hline & Alopecia $^{a}$ \\
\hline & $\begin{array}{l}\text { Sweet's syndrome (acute febrile } \\
\text { neutrophilic dermatosis) }\end{array}$ \\
\hline \multirow[t]{4}{*}{ Ophthalmological } & Episcleritis \\
\hline & Uveitis \\
\hline & Cataracts $^{\mathrm{a}}$ \\
\hline & Increased intraocular pressure ${ }^{a}$ \\
\hline \multirow[t]{7}{*}{ Hematological } & Coagulation abnormalities \\
\hline & Iron deficiency anemia \\
\hline & Autoimmune hemolytic anemia $^{a}$ \\
\hline & Neutropenia $^{a}$ \\
\hline & Thrombocytosis \\
\hline & Immune thrombocytopenic purpura \\
\hline & Thromboembolic disease \\
\hline \multirow[t]{2}{*}{$\begin{array}{l}\text { Growth and } \\
\text { development }\end{array}$} & Growth failure $^{a}$ \\
\hline & Pubertal delay \\
\hline Renal & Nephrolithiasis \\
\hline Pancreas & Pancreatitis $^{\mathrm{a}}$ \\
\hline \multirow[t]{2}{*}{ Cardiorespiratory } & Pericarditis $^{\mathrm{a}}$ \\
\hline & Pneumonitis $^{\mathrm{a}}$ \\
\hline Other & Amyloidosis \\
\hline
\end{tabular}

${ }^{\text {a } M a y ~ b e ~ d u e ~ t o ~ s i d e ~ e f f e c t s ~ o f ~ m e d i c a l ~ t h e r a p i e s . ~ A d a p t e d ~ f r o m ~}$ Leichtner and Higuchi ${ }^{6}$ and Croft. ${ }^{17}$

with high-dose steroids. These patients require close monitoring with serial physical examination and periodic (every 8-12 hours) supine and upright radiographs to assess colonic distention and exclude the presence of intra-abdominal free air. A nasogastric/jejunal tube may decompress the colon and minimize fluid buildup. Limited pediatric controlled studies suggest that enteral feeds may be safe in these patients and 
may be preferable to the risks of complications from parenteral nutrition. ${ }^{28}$ Those patients with toxic megacolon who fail to respond to these aggressive medical measures and have persistence of toxic dilatation for longer than 48 hours, perforation, or ongoing hemorrhage may require emergency colectomy. ${ }^{26,27}$

Severe hemorrhage in UC may occur with or without toxic megacolon. This is managed with transfusions blood products and aggressive treatment for the underlying UC. Massive hemorrhage in UC or perforation (with or without toxic megacolon) can necessitate urgent colectomy. ${ }^{29,30}$

A colonic stricture can occur in long-standing UC. Although UC strictures in adults may be due to carcinoma, children with UC most likely have benign postinflammatory fibrotic strictures. These strictures usually occur in the distal colon, may involve smooth muscle hypertrophy, and are potentially reversible. ${ }^{31-33}$

There is a well-established risk of colorectal carcinoma in patients with UC. This risk increases with longer duration of disease and more extensive colonic involvement. ${ }^{34,35}$ A metaanalysis of more than 116 studies suggests a cumulative incidence of colorectal carcinoma in all patients with UC of $2 \%$ at 10 years, $8 \%$ at 20 years, and $18 \%$ after 30 years of disease. ${ }^{36}$ Childhood onset of UC has not been consistently demonstrated to be an independent risk factor for colorectal cancer. ${ }^{37}$ The risk of colorectal cancer is highest in patients with pancolitis, intermediate in patients with left-sided colitis, and minimal in patients with proctitis or proctosigmoiditis. ${ }^{36}$ Other risk factors that suggested to predispose UC patients to colorectal cancer in patients include concurrent primary sclerosing cholangitis, ${ }^{38-40}$ a family history of colorectal cancer, ${ }^{41}$ and the occurrence of backwash ileitis. $^{42}$

\section{Medical Management of Pediatric Ulcerative Colitis}

There are two major phases in the medical treatment of UC: first, induction of remission, and, second, maintenance of remission (-Table 2 ). Treatments for induction depend on the extent and severity of disease. For the minority of children with limited distal disease (proctitis), topical/rectal aminosalicylates may be an effective but cumbersome treatment. For more extensive but mild disease, oral aminosalicylates can be initiated with close supervision of patients who may deteriorate or not respond to this therapy. Early treatment with oral steroids should be considered for these patients or for those with more extensive disease.

Patients with fulminant colitis require inpatient treatment (parenteral fluids/steroids) and joint management with pediatric surgeons. There are international evidencebased consensus guidelines for managing acute severe UC. ${ }^{43}$ These recommendations suggest that clinicians use an algorithmic approach for children with acute severe UC based daily scoring of the Pediatric Ulcerative Colitis Activity Index (PUCAI) $^{44}$ (- Table 3) for initial evaluation, medical therapy, surgical considerations, and discharge recommendations. ${ }^{43}$ This standardized approach to management of UC may allow for effective monitoring of disease progress and timely treatment escalation when needed. ${ }^{43}$

The second phase of therapy is the maintenance of remission. For most patients, aminosalicylates are the first choice for maintenance therapy. Maintenance treatment with thiopurines (6-MP or azathioprine) should be considered for children with frequent relapses requiring steroid therapy. Remission of distal colitis (proctitis or proctosigmoiditis) may be maintained by topical therapy, although oral aminosalicylates are generally more tolerated by children. ${ }^{45}$ There is currently no evidence supporting the use of methotrexate or antibiotics as maintenance therapy for UC in children or adults. ${ }^{46,47}$ Cyclosporine and tacrolimus are inhibitors of cell-medicated immunity through blockage of calcineurin. A Cochrane review from 2005 reported that the evidence for cyclosporine preventing colectomy in the medium to long term was weak despite frequent short-term improvement. ${ }^{48}$ Limited uncontrolled data for the use of cyclosporine in children with UC report short-term response in $80 \%$ of patients, ${ }^{49}$ but the majority of patients will proceed to colectomy within 1 year. In one uncontrolled study on children, tacrolimus demonstrated a response rate of $69 \%$ and similar high rates of surgery within 1 year. ${ }^{50}$ Short-term and 1 -year colectomy rates have declined since the use of infliximab in children with acute severe UC to $9 \%$ by discharge and $19 \%$ by 1 year. ${ }^{51}$

Table 2 Medical therapy of ulcerative colitis

\begin{tabular}{|l|l|l|}
\hline Disease extent and severity & Induction phase & Maintenance phase \\
\hline Distal colitis & $\begin{array}{l}\text { Topical aminosalicylates (suppositories for proctitis) } \\
\text { Topical steroids } \\
\text { Oral aminosalicylates } \\
\text { Oral steroids }\end{array}$ & $\begin{array}{l}\text { Intermittent topical aminosalicylates } \\
\text { Oral aminosalicylates } \\
\text { Thiopurines: azathioprine/6-MP }\end{array}$ \\
\hline Extensive colitis & $\begin{array}{l}\text { Oral aminosalicylates } \\
\text { Oral steroids }\end{array}$ & Oral aminosalicylates \\
\hline Mild to moderate & Oral steroids & Thiopurines: Azathioprine/6-MP \\
\hline Moderate to severe & $\begin{array}{l}\text { Parenteral steroids } \\
\text { Infliximab } \\
\text { Cyclosporine/tacrolimus } \\
\text { surgery }\end{array}$ & $\begin{array}{l}\text { Oral aminosalicylates } \\
\text { Thiopurines: Azathioprine/6-MP } \\
\text { Infliximab }\end{array}$ \\
\hline Fulminant & \begin{tabular}{l} 
\\
\hline
\end{tabular}
\end{tabular}

Adapted from Leichtner and Higuchi ${ }^{6}$ and Croft. ${ }^{17}$ 
Table 3 Pediatric Ulcerative Colitis Activity Index (PUCAI)

\begin{tabular}{|c|c|}
\hline Item & Points \\
\hline \multicolumn{2}{|l|}{ Abdominal pain } \\
\hline No pain & 0 \\
\hline Pain can be ignored & 5 \\
\hline Pain cannot be ignored & 10 \\
\hline \multicolumn{2}{|l|}{ Rectal bleeding } \\
\hline None & 0 \\
\hline $\begin{array}{l}\text { Small amount only } \\
\text { in }<50 \% \text { of stools }\end{array}$ & 10 \\
\hline Small amount with most stools & 20 \\
\hline $\begin{array}{l}\text { Large amount } \\
(>50 \% \text { of the stool content) }\end{array}$ & 30 \\
\hline \multicolumn{2}{|l|}{ Stool consistency of most stools } \\
\hline Formed & 0 \\
\hline Partially formed & 5 \\
\hline Completely unformed & 10 \\
\hline \multicolumn{2}{|l|}{ Number of stools in $24 \mathrm{~h}$} \\
\hline $0-2$ & 0 \\
\hline $3-5$ & 5 \\
\hline $6-8$ & 10 \\
\hline$>8$ & 15 \\
\hline \multicolumn{2}{|c|}{ Nocturnal stools (any episode causing wakening) } \\
\hline No & 0 \\
\hline Yes & 10 \\
\hline \multicolumn{2}{|l|}{ Activity level } \\
\hline No limitation of activity & 0 \\
\hline Occasional limitation of activity & 5 \\
\hline Severe restricted activity & 10 \\
\hline Sum of PUCAI (0-85) & \\
\hline
\end{tabular}

\section{Surgical Management of Pediatric Ulcerative Colitis}

\section{Indications for Operation}

In contrast to adults, pancolitis at the time of presentation is the rule rather than the exception in children. At least $25 \%$ of children and adolescents hospitalized with UC require urgent or emergent operation for persistent or escalating, symptomatic colitis despite optimal medical management. Historical symptoms and objective clinical signs of pediatric UC should be quantified with acute severe disease generally characterized by a PUCAI score of 65 to $85 .{ }^{44}$ PUCAI scoring is also useful in determining the efficacy and progress of treatment for acute severe colitis. Contemporary, multidisciplinary management is characterized by involvement of pediatric specialists with expertise in gastroenterology, surgery, radiology, nursing, nutrition, and psychology. Indications for operative management in pediatric UC include three broad, overlapping categories: (1) failure of medical management,
Table 4 Indications for operative management in pediatric ulcerative colitis

\begin{tabular}{|l|}
\hline Failure of medical management \\
\hline Lack of medical compliance \\
\hline $\begin{array}{l}\text { Complications, adverse reaction, or allergies to drug } \\
\text { regimens }\end{array}$ \\
\hline Uncontrollable disease despite optimal medical regimen \\
\hline Disease-related morbidity/complications \\
\hline Malnutrition/growth arrest \\
\hline Hematochezia/gastrointestinal hemorrhage \\
\hline Sepsis \\
\hline Toxic megacolon or intestinal perforation \\
\hline Dysplasia \\
\hline Quality of life \\
\hline Chronic abdominal pain \\
\hline Uncontrollable stool frequency, tenesmus \\
\hline Chronic absence from school, social events \\
\hline $\begin{array}{l}\text { Need for repetitive and/or prolonged hospitalization to } \\
\text { control symptoms }\end{array}$ \\
\hline
\end{tabular}

(2) disease-related morbidity and/or complications, and (3) quality of life (-Table 4).

Failure of medical management may occur secondary to lack of compliance or uncontrollable, progressive disease despite escalation of optimal medical therapy. A small but significant proportion of children and adolescents will have drug-related complications, allergies, or adverse reactions, making further medical management impractical. It is important to recognize that while medical management is preferable in most pediatric patients with moderate-tosevere disease, operative management will be necessary in a substantial number of children. In a multicenter cohort study conducted on 322 children with UC in the Pediatric Inflammatory Bowel Disease Collaborative Research Group Registry, the use of infliximab led to corticosteroid-free, inactive disease in $38 \%$ at 12 months and in $21 \%$ at 24 months; however, $39 \%$ of patients required colectomy by 24 months. ${ }^{52}$ Therefore, in pediatric patients with acute severe disease, the significant probability of the need for colectomy warrants prospective discussion with a pediatric surgeon.

Similar to adult disease, pediatric UC may lead to diseaserelated morbidity and complications including gastrointestinal hemorrhage, sepsis, intestinal perforation, toxic megacolon, and with long-standing disease, dysplasia. Life-threatening hemorrhage, sepsis, perforation, or colonic dilatation mandates emergent surgical evaluation and may require urgent colectomy. Abdominal radiographs should be obtained in any child with UC presenting with systemic sepsis. The presence of transverse colonic dilatation of greater than $56 \mathrm{~mm}$ with systemic sepsis is diagnostic for toxic megacolon, and urgent colectomy is warranted if symptoms worsen or fail to improve within 48 hours. ${ }^{43}$ In the absence of colonic dilatation, children hospitalized with acute fulminant colitis failing to respond to 
medical therapy should undergo colectomy during the same hospitalization.

A unique issue related to pediatric IBD includes disruption of normal growth velocity in both height and weight. This appears to have myriad etiologies, including the effects of a primary systemic inflammatory condition, decreased nutrition secondary to symptomatic colitis, and the use of steroids. ${ }^{53}$ Accurate, quantitative monitoring of growth is an essential clinical evaluation in all children and adolescents with UC; this includes longitudinal documentation of height and weight on standard growth charts and radiological evaluation of skeletal age assessment as needed. ${ }^{54}$ Treatment efforts in the prepubertal or pubertal child with UC are therefore targeted at rapid and effective remission. Persistent, symptomatic disease associated with growth failure should be considered an indication for colectomy. The window of opportunity to reverse growth failure during puberty is narrow, and if not addressed by inducing clinical remission with medical, and when necessary, surgical management, the impact on height may be irreversible. As discussed previously, colon cancer is rare in pediatric UC. Similar to adults, biopsy-proven dysplasia is also an absolute indication for colectomy. ${ }^{55}$

The constellation of symptomatic UC in a child may include chronic abdominal pain, tenesmus, and uncontrollable stool frequency leading to disruption of normal activities, including school and sleep. Chronic absence from school, athletics, and social events due to the need for repetitive and/or prolonged hospitalization to control symptoms often leads to a significantly decreased quality of life for both patient and parents. The decision to proceed with colectomy is often driven by a prolonged inpatient hospitalization for refractory disease.

\section{Operative Management}

Operative management in pediatric UC is generally reserved for the most ill children and adolescents with medically refractory disease, making urgent and emergent colectomy relatively more common in comparison to adults. Elective colectomy in pediatric UC is less common and generally guided by quality of life issues; in rare instances, elective colectomy is performed for dysplasia or carcinoma identified by routine surveillance biopsy. Many children and families view the need for an operation as a failure, and medical management may be prolonged to allow for physiological and emotional adaptation. These children may have clinically significant preoperative issues due to progressive weight loss, nutrition, pain, anemia, and psychological stress. Essential perioperative management principles include devising nutritional support strategies, provision of judicious analgesia, transfusion when necessary, and provision of age-appropriate psychological support. However, delay in surgical intervention to optimize nutritional status is not recommended. Therefore, timing of operative intervention for pediatric UC should account for symptom severity based upon disease activity index, perceived and measurable quality of life, surgeon experience, and patient/parent preferences.

Children and adolescents requiring operative intervention should be given perioperative, prophylactic, broad-spectrum, intravenous antibiotics to reduce the risk of surgical site infection. There appears to be an increased risk of deep venous thrombosis in adolescents and adults with IBD, and appropriate preventive measures, including mechanical pneumatic devices and/or chemical prophylaxis, should be deployed. ${ }^{56,57}$ Symptomatic pediatric UC can be well treated surgically with acceptable morbidity and demonstrated excellent long-term outcomes. Contemporary operative management through minimally invasive techniques for all stages of operative care is used at many hospitals with children's surgical expertise. ${ }^{58}$ The ultimate aim of operative management is to remove the colon and rectum and restore gastrointestinal continuity with preservation of anal sphincter integrity and function. Along with generalized illness, immunosuppression with high-dose steroids and/or the use of biological agents that blunt the inflammatory response to injury and infection makes a staged operative approach preferable in most pediatric patients. In the urgent or emergent setting, laparoscopic or open subtotal colectomy with diverting end ileostomy is the preferred initial operation.

Following colectomy with ileostomy, most pediatric patients require several weeks to months of physiological recovery given their illness severity. Moderately frequent follow-up is necessary to monitor weight, nutritional status, stool output, and serum electrolytes. Definitive gastrointestinal reconstruction is most commonly performed by laparoscopic completion proctectomy, creation of an ileal reservoir, and ileal pouch-anal anastomosis (IPAA). Using the terminal ileum, there are several reservoir or pouch configurations described; the most commonly created reservoir is the ileal J-pouch. Creation of a distal ileal J-pouch helps reduce short-term stool frequency and rates of urgency and nocturnal incontinence in the first postoperative year compared with straight ileoanal reconstruction. These differences tend to diminish over time, and therefore decisions between these two approaches should reflect consideration of the patient's age, lifestyle, preference, and surgeon experience. An ileal J-pouch is constructed by reflecting the terminal ileum upon itself for a distance of 8 to $12 \mathrm{~cm}$, dividing the common wall and performing a side-to-side anastomosis with a linear stapler or sutures to create a pouch. An anastomosis is then created between the distal apex of the ileal J-pouch and the anus. Through a laparoscopic approach, the J-pouch may be constructed in extracorporeal fashion by eviscerating the terminal ileum through the ileostomy site or alternatively through a suprapubic operative site. Care must be taken to ensure adequate mesenteric length for the pouch to easily reach the perineum without compromising the vascular supply to the distal ileum. Mesenteric alignment must be directly visualized and confirmed prior to creating the IPAA. Routine anastomotic leak testing with either transrectal fluid instillation or air insufflation is highly recommended. ${ }^{59,60}$

Definitive management of pediatric UC historically includes transanal, distal mucosectomy-this may be performed using an endorectal technique that excises the distal rectal mucosa and preserves the rectal muscularis and the surrounding anal sphincter muscle complex. The use of colectomy with sphincter preservation and ileoanal anastomosis (anal ileostomy) for benign colorectal disease was initially reported in $1948 .{ }^{61}$ In a child or adult, endorectal mucosectomy makes fecal incontinence, and 
urinary and sexual dysfunction less likely compared with complete perineal proctectomy. The use of endorectal dissection in children with UC was popularized in 1978 by Martin and LeCoultre, who applied the dissection technique described for the treatment of Hirschsprung disease by Soave. ${ }^{62}$ In adults, a contemporary trend in preserving the distal 1 to $2 \mathrm{~cm}$ of anorectal mucosa in the anal transition zone was largely driven by the use of end-to-end staplers in creating the IPAA using a double-stapled technique. Early, prospective randomized clinical trials demonstrated no differences in complications or early functional results between mucosectomy and hand-sewn versus double-stapled techniques, the latter preserving the distal anorectal mucosa. ${ }^{63,64}$ In a large case series comparing hand-sewn to stapled IPAA in 3,109 adult patients, a stapled IPAA had better outcomes and measured quality of life related to less incontinence, stool seepage, pad usage, and fewer restrictions in diet, social activities, and work compared with hand-sewn anastomosis. ${ }^{65}$ In children and adolescents, we have found stapled IPAA to yield superior results in preservation of fecal continence, sensation, reduction of fecal smearing, and subjective quality of life compared with complete mucosectomy. Importantly, retention of the anal transition zone mucosa must be balanced with the potential for persistent inflammation or "cuffitis" and ultimately developing dysplasia within the retained mucosa. This has led some authors to advocate complete rectal mucosectomy in all children. ${ }^{66}$ Based upon 10-year longitudinal follow-up, the risk of developing dysplasia in the anal transition zone is estimated to be approximately $4.5 \%$ in adults, and is particularly relevant if the colectomy is being performed for biopsy-proven dysplasia or cancer. This would be a distinctly unusual clinical scenario in pediatric UC. To summarize, retention of the anal transition zone using a double-stapled technique for restorative IPAA may provide for improved quality of life in children and adolescents. Preservation of the anal transition zone, however, mandates continued endoscopic surveillance throughout adulthood. Dysplasia or persistent, symptomatic inflammation of the anal transition zone remains surgically treatable with transanal mucosectomy and ileal pouch advancement. 67

\section{Surgical Outcomes}

Postoperative complications are common and reflect the initial operative urgency for colectomy in a relatively ill population, coupled with the magnitude and relative complexity of the procedures required to restore gastrointestinal continuity. These complications include anastomotic leak or stenosis, infection, operative hemorrhage, and small bowel obstruction. Bladder dysfunction, impotence, dyspareunia, infertility, and ileovesical or ileovaginal fistula have also been observed. In females, impairment of fertility was often attributed to the development of pelvic adhesive scar tissue from the operations necessary to create the ileoanal anastomosis. Pregnancy rates appear to be significantly higher in women undergoing laparoscopic IPAA compared with open restorative proctocolectomy, making this approach ideal in the adolescent population. ${ }^{68}$ Complete pouch failure is observed in approximately 5 to $7 \%$ of pediatric patients and appears to be more common in the setting of colectomy and reconstruction for indeterminate colitis; ultimately, some of these children and adolescents will prove to have phenotypic Crohn's disease.

Excellent outcomes have been reported using staged total abdominal proctocolectomy with ileoanal pouch reconstructive procedures in children and adolescents. Reasonable long-term functional goals are normal fecal continence, stool frequency of four to six bowel movements per day and 0 to 1 bowel movement at night, and normal urinary and sexual function. This is achievable in almost $60 \%$ of patients. ${ }^{69}$ The remainder of patients will have a spectrum of incontinence, urgency, and fecal soiling that require adaptive management. Approximately $15 \%$ will have daytime fecal seepage or need to use pads at night, with associated limitations in work, social, and sexual activities. Most children and adolescents will require modification of eating behaviors for optimal outcome, and, in particular, avoidance of late night meals, to reduce nocturnal bowel movements and fecal seepage. Initially, following IPAA, antidiarrheal medications, such as loperamide or diphenoxylate, and supplemental bulk fiber agents are commonly used. More than 92\% of pediatric patients are highly satisfied with procedural results and would recommend IPAA surgery to others. ${ }^{69}$ A survey study of 32 pediatric patients undergoing colectomy and ileoanal pullthrough for UC or familial adenomatous polyposis reported a health-related quality of life that was indistinguishable from the age-matched, general population. ${ }^{70}$

\section{Management of Pouchitis}

Pouchitis, or inflammation of the newly created ileal reservoir, is the most significant chronic complication in UC patients undergoing IPAA. Adult studies report that approximately $40 \%$ of patients will have a single episode of pouchitis, $15 \%$ will have recurrent pouchitis, and 5\% will develop chronic pouchitis. ${ }^{71}$ Symptoms of pouchitis include diarrhea, hematochezia, abdominal cramping, urgency and incontinence of stool, fatigue, and fever. ${ }^{72}$ Patients with UC who undergo IPAA have pouchitis more commonly than patients with familial polyposis who undergo this surgery. ${ }^{73}$ Children and adults with extraintestinal manifestations of UC, especially primary sclerosing cholangitis, ${ }^{74,75}$ may experience higher rates of pouchitis. Patients with pouchitis symptoms frequently demonstrate biochemical signs of anemia and an elevated erythrocyte sedimentation rate. The definitive diagnosis pouchitis is established by histology through flexible sigmoidoscopy of the pouch with biopsies.

The first-line treatment for pouchitis is typically broadspectrum antibiotics. ${ }^{76,77}$ Metronidazole is the most commonly used antibiotic, but alternative agents include ciprofloxacin, amoxicillin-clavulanic acid, erythromycin, and tetracycline. ${ }^{77}$ If there is no improvement with antibiotics, other options include enemas (mesalamine/steroid) or oral therapy with aminosalicylates or steroids. ${ }^{78}$ Other described therapies for refractory pouchitis include cyclosporine enemas, short-chain fatty acid enemas, butyrate suppositories, and glutamine suppositories. $^{79-81}$ After ileostomy closure, probiotic therapy may prevent the onset of acute pouchitis and maintain remission of chronic pouchitis. ${ }^{82}$ 


\section{Conclusion}

In summary, children and adolescents presenting with UC have unique symptoms and issues that are often distinct from adults. While the medical and surgical management is similar for pediatric and adult UC patients, the unique aspects of developmental age, psychosocial factors, and growth in children are significant issues in optimizing medical and surgical treatment strategies. Therefore, multidisciplinary management in a pediatric-specific setting is highly desirable. Children and adolescents undergoing operative treatment for UC should be expected to have excellent long-term physiological function and quality of life outcomes.

\section{References}

1 Kugathasan S, Judd RH, Hoffmann RG, et al; Wisconsin Pediatric Inflammatory Bowel Disease Alliance. Epidemiologic and clinical characteristics of children with newly diagnosed inflammatory bowel disease in Wisconsin: a statewide population-based study. J Pediatr 2003;143(04):525-531

2 Adamiak T, Walkiewicz-Jedrzejczak D, Fish D, et al. Incidence, clinical characteristics, and natural history of pediatric IBD in Wisconsin: a population-based epidemiological study. Inflamm Bowel Dis 2013;19(06):1218-1223

3 Benchimol EI, Guttmann A, Griffiths AM, et al. Increasing incidence of paediatric inflammatory bowel disease in Ontario, Canada: evidence from health administrative data. Gut 2009;58 (11):1490-1497

4 Abramson O, Durant M, Mow W, et al. Incidence, prevalence, and time trends of pediatric inflammatory bowel disease in Northern California, 1996 to 2006. J Pediatr 2010;157(02):233-239.e1

5 Kelley-Quon LI, Jen HC, Ziring DA, et al. Predictors of proctocolectomy in children with ulcerative colitis. J Pediatr Gastroenterol Nutr 2012;55(05):534-540

6 Leichtner AM, Higuchi S. Ulcerative colitis. In: Walker WA, Goulet $\mathrm{O}$, et al, eds. Pediatric Gastrointestinal Disease. Hamilton, Ontario: B. C. Decker Inc.; 2004:825-849

7 Grand RJ, Homer DR. Approaches to inflammatory bowel disease in childhood and adolescence. Pediatr Clin North Am 1975;22 (04):835-850

8 Motil KJ, Grand RJ. Ulcerative colitis and Crohn disease in children. Pediatr Rev 1987;9(04):109-120

9 Werlin SL, Grand RJ. Severe colitis in children and adolescents: diagnosis. Course, and treatment. Gastroenterology 1977;73 (4 Pt 1):828-832

10 Rao SS, Holdsworth CD, Read NW. Symptoms and stool patterns in patients with ulcerative colitis. Gut 1988;29(03):342-345

11 Mir-Madjlessi SH, Michener WM, Farmer RG. Course and prognosis of idiopathic ulcerative proctosigmoiditis in young patients. J Pediatr Gastroenterol Nutr 1986;5(04):571-575

12 Langholz E, Munkholm P, Davidsen M, Nielsen OH, Binder V. Changes in extent of ulcerative colitis: a study on the course and prognostic factors. Scand J Gastroenterol 1996;31(03):260-266

13 Hyams J, Davis P, Lerer T, et al. Clinical outcome of ulcerative proctitis in children. J Pediatr Gastroenterol Nutr 1997;25(02):149-152

14 Meucci G, Vecchi M, Astegiano M, et al. The natural history of ulcerative proctitis: a multicenter, retrospective study. Gruppo di Studio per le Malattie Infiammatorie Intestinali (GSMII). Am J Gastroenterol 2000;95(02):469-473

15 Tobin JM, Sinha B, Ramani P, Saleh AR, Murphy MS. Upper gastrointestinal mucosal disease in pediatric Crohn disease and ulcerative colitis: a blinded, controlled study. J Pediatr Gastroenterol Nutr 2001;32(04):443-448
16 Sharif F, McDermott M, Dillon M, et al. Focally enhanced gastritis in children with Crohn's disease and ulcerative colitis. Am J Gastroenterol 2002;97(06):1415-1420

17 Croft NM. Ulcerative and indeterminate colitis. In: Kleinman RE, Sanderson IR, Goulet O, et al, eds. Walker's Pediatric Gastrointestinal Disease. Hamilton, Ontario: B. C. Decker Inc.; 2008:545-557

18 Greenstein AJ, Janowitz HD, Sachar DB. The extra-intestinal complications of Crohn's disease and ulcerative colitis: a study of 700 patients. Medicine (Baltimore) 1976;55(05):401-412

19 Hyams JS. Extraintestinal manifestations of inflammatory bowel disease in children. J Pediatr Gastroenterol Nutr 1994;19(01): 7-21

20 Berger M, Gribetz D, Korelitz BI. Growth retardation in children with ulcerative colitis: the effect of medical and surgical therapy. Pediatrics 1975;55(04):459-467

21 Motil KJ, Grand RJ. The epidemiology of growth failure in children and adolescents with inflammatory bowel disease. Gastroenterology 1983;84:1254

22 Jalan KN, Sircus W, Card WI, et al. An experience of ulcerative colitis. I. Toxic dilation in 55 cases. Gastroenterology 1969;57(01):68-82

23 Fazio VW. Toxic megacolon in ulcerative colitis and Crohn's colitis. Clin Gastroenterol 1980;9(02):389-407

24 Sheth SG, LaMont JT. Toxic megacolon. Lancet 1998;351 (9101):509-513

25 Present DH. Toxic megacolon. Med Clin North Am 1993;77(05): $1129-1148$

26 Norland CC, Kirsner JB. Toxic dilatation of colon (toxic megacolon): etiology, treatment and prognosis in 42 patients. Medicine (Baltimore) 1969;48(03):229-250

27 Brown JW. Toxic megacolon associated with loperamide therapy. JAMA 1979;241(05):501-502

28 Kugathasan S, Dubinsky MC, Keljo D, et al. Severe colitis in children. J Pediatr Gastroenterol Nutr 2005;41(04):375-385

29 Jewell DP, Caprilli R, Mortensen N, et al. Indications and timing of surgery for severe ulcerative colitis. Gastroenterol Int 1991; 4:161-164

30 Greenstein AJ, Barth JA, Sachar DB, Aufses AH Jr. Free colonic perforation without dilatation in ulcerative colitis. Am J Surg 1986;152(03):272-275

31 Caroline DF, Evers K. Colitis: radiographic features and differentiation of idiopathic inflammatory bowel disease. Radiol Clin North Am 1987;25(01):47-66

32 Gumaste V, Sachar DB, Greenstein AJ. Benign and malignant colorectal strictures in ulcerative colitis. Gut 1992;33(07): 938-941

33 Horton KM, Jones B, Fishman EK. Imaging of the inflammatory bowel diseases. In: Kirsner JB, editor. Inflammatory bowel diseases. Philadelphia, PA: WB Saunders; 2000:479-500

34 Broström O, Löfberg R, Nordenvall B, Ost A, Hellers G. The risk of colorectal cancer in ulcerative colitis. An epidemiologic study. Scand J Gastroenterol 1987;22(10):1193-1199

35 Gilat T, Fireman Z, Grossman A, et al. Colorectal cancer in patients with ulcerative colitis. A population study in central Israel. Gastroenterology 1988;94(04):870-877

36 Eaden JA, Abrams KR, Mayberry JF. The risk of colorectal cancer in ulcerative colitis: a meta-analysis. Gut 2001;48(04):526-535

37 Eaden JA, Mayberry JF. Colorectal cancer complicating ulcerative colitis: a review. Am J Gastroenterol 2000;95(10):2710-2719

38 Broomé U, Löfberg R, Veress B, Eriksson LS. Primary sclerosing cholangitis and ulcerative colitis: evidence for increased neoplastic potential. Hepatology 1995;22(05):1404-1408

39 Brentnall TA, Haggitt RC, Rabinovitch PS, et al. Risk and natural history of colonic neoplasia in patients with primary sclerosing cholangitis and ulcerative colitis. Gastroenterology 1996;110 (02):331-338

40 Jayaram H, Satsangi J, Chapman RW. Increased colorectal neoplasia in chronic ulcerative colitis complicated by primary sclerosing cholangitis: fact or fiction? Gut 2001;48(03):430-434 
41 Askling J, Dickman PW, Karlén P, et al. Family history as a risk factor for colorectal cancer in inflammatory bowel disease. Gastroenterology 2001;120(06):1356-1362

42 Heuschen UA, Hinz U, Allemeyer EH, et al. Backwash ileitis is strongly associated with colorectal carcinoma in ulcerative colitis. Gastroenterology 2001;120(04):841-847

43 Turner D, Travis SP, Griffiths AM, et al; European Crohn's and Colitis Organization; Porto IBD Working Group, European Society of Pediatric Gastroenterology, Hepatology, and Nutrition. Consensus for managing acute severe ulcerative colitis in children: a systematic review and joint statement from ECCO, ESPGHAN, and the Porto IBD Working Group of ESPGHAN. Am J Gastroenterol 2011;106(04):574-588

44 Turner D, Otley AR, Mack D, et al. Development, validation, and evaluation of a pediatric ulcerative colitis activity index: a prospective multicenter study. Gastroenterology 2007;133 (02):423-432

45 Escher JC, Taminiau JA, Nieuwenhuis EE, Büller HA, Grand RJ. Treatment of inflammatory bowel disease in childhood: best available evidence. Inflamm Bowel Dis 2003;9(01):34-58

46 Lichtenstein GR, Abreu MT, Cohen R, Tremaine W; American Gastroenterological Association. American Gastroenterological Association Institute technical review on corticosteroids, immunomodulators, and infliximab in inflammatory bowel disease. Gastroenterology 2006;130(03):940-987

47 Perencevich M, Burakoff R. Use of antibiotics in the treatment of inflammatory bowel disease. Inflamm Bowel Dis 2006;12(07): 651-664

48 Shibolet O, Regushevskaya E, Brezis M, Soares-Weiser K. Cyclosporine A for induction of remission in severe ulcerative colitis. Cochrane Database Syst Rev 2005;(01):CD004277

49 Treem WR, Cohen J, Davis PM, Justinich CJ, Hyams JS. Cyclosporine for the treatment of fulminant ulcerative colitis in children. Immediate response, long-term results, and impact on surgery. Dis Colon Rectum 1995;38(05):474-479

50 Bousvaros A, Kirschner BS, Werlin SL, et al. Oral tacrolimus treatment of severe colitis in children. J Pediatr 2000;137(06): 794-799

51 Turner D, Mack D, Leleiko N, et al. Severe pediatric ulcerative colitis: a prospective multicenter study of outcomes and predictors of response. Gastroenterology 2010;138(07):2282-2291

52 Hyams JS, Lerer T, Griffiths A, et al; Pediatric Inflammatory Bowel Disease Collaborative Research Group. Outcome following infliximab therapy in children with ulcerative colitis. Am J Gastroenterol 2010;105(06):1430-1436

53 Heuschkel R, Salvestrini C, Beattie RM, Hildebrand H, Walters T, Griffiths A. Guidelines for the management of growth failure in childhood inflammatory bowel disease. Inflamm Bowel Dis 2008; 14(06):839-849

54 Abraham BP, Mehta S, El-Serag HB. Natural history of pediatriconset inflammatory bowel disease: a systematic review. J Clin Gastroenterol 2012;46(07):581-589

55 Sato TT, Oldham KT. Pediatric abdomen. In: Mulholland MW, Lillemoe KD, Doherty GM, Maier RV, Upchurch GR, eds. Greenfield's Surgery: Scientific Principles and Practice. 4th ed. Philadelphia, PA: Lippincott Williams \& Wilkins; 2006

56 Merrill A, Millham F. Increased risk of postoperative deep vein thrombosis and pulmonary embolism in patients with inflammatory bowel disease: a study of National Surgical Quality Improvement Program patients. Arch Surg 2012;147(02):120-124

57 Nylund CM, Goudie A, Garza JM, Crouch G, Denson LA. Venous thrombotic events in hospitalized children and adolescents with inflammatory bowel disease. J Pediatr Gastroenterol Nutr 2013; 56(05):485-491

58 Georgeson KE. Laparoscopic-assisted total colectomy with pouch reconstruction. Semin Pediatr Surg 2002;11(04):233-236

59 Kwon S, Morris A, Billingham R, et al; Surgical Care and Outcomes Assessment Program (SCOAP) Collaborative. Routine leak testing in colorectal surgery in the Surgical Care and Outcomes Assessment Program. Arch Surg 2012;147(04):345-351

60 Kirat HT, Remzi FH. Technical aspects of ileoanal pouch surgery in patients with ulcerative colitis. Clin Colon Rectal Surg 2010;23 (04):239-247

61 Ravitch MM. Anal ileostomy with sphincter preservation in patients requiring total colectomy for benign conditions. 1948 Dis Colon Rectum 1990;33(06):529-538

62 Martin LW, LeCoultre C. Technical considerations in performing total colectomy and Soave endorectal anastomosis for ulcerative colitis. J Pediatr Surg 1978;13(6D):762-764

63 Luukkonen P, Järvinen H. Stapled vs hand-sutured ileoanal anastomosis in restorative proctocolectomy. A prospective, randomized study. Arch Surg 1993;128(04):437-440

64 Reilly WT, Pemberton JH, Wolff BG, et al. Randomized prospective trial comparing ileal pouch-anal anastomosis performed by excising the anal mucosa to ileal pouch-anal anastomosis performed by preserving the anal mucosa. Ann Surg 1997;225(06): 666-676, discussion 676-677

65 Kirat HT, Remzi FH, Kiran RP, Fazio VW. Comparison of outcomes after hand-sewn versus stapled ileal pouch-anal anastomosis in 3,109 patients. Surgery 2009;146(04):723-729, discussion 729-730

66 Uchida K, Araki T, Kusunoki M. History of and current issues affecting surgery for pediatric ulcerative colitis. Surg Today 2013; 43(11):1219-1231

67 Remzi FH, Fazio VW, Delaney CP, et al. Dysplasia of the anal transitional zone after ileal pouch-anal anastomosis: results of prospective evaluation after a minimum of ten years. Dis Colon Rectum 2003;46(01):6-13

68 Bartels SA, D’Hoore A, Cuesta MA, Bensdorp AJ, Lucas C, Bemelman WA. Significantly increased pregnancy rates after laparoscopic restorative proctocolectomy: a cross-sectional study. Ann Surg 2012;256(06):1045-1048

69 Ozdemir Y, Kiran RP, Erem HH, et al. Functional outcomes and complications after restorative proctocolectomy and ileal pouch anal anastomosis in the pediatric population. J Am Coll Surg 2014; 218(03):328-335

70 Shamberger RC, Masek BJ, Leichtner AM, Winter HS, Lillehei CW. Quality-of-life assessment after ileoanal pull-through for ulcerative colitis and familial adenomatous polyposis. J Pediatr Surg 1999;34(01):163-166

71 Sandborn WJ. Pouchitis following ileal pouch-anal anastomosis: definition, pathogenesis, and treatment. Gastroenterology 1994; 107(06):1856-1860

72 Mahadevan U, Sandborn WJ. Diagnosis and management of pouchitis. Gastroenterology 2003;124(06):1636-1650

73 Kartheuser AH, Parc R, Penna CP, et al. Ileal pouch-anal anastomosis as the first choice operation in patients with familial adenomatous polyposis: a ten-year experience. Surgery 1996; 119(06):615-623

74 Penna C, Dozois R, Tremaine W, et al. Pouchitis after ileal pouchanal anastomosis for ulcerative colitis occurs with increased frequency in patients with associated primary sclerosing cholangitis. Gut 1996;38(02):234-239

75 Faubion WA Jr, Loftus EV, Sandborn WJ, Freese DK, Perrault J. Pediatric "PSC-IBD": a descriptive report of associated inflammatory bowel disease among pediatric patients with PSC. J Pediatr Gastroenterol Nutr 2001;33(03):296-300

76 Gionchetti P, Amadini C, Rizzello F, Venturi A, Campieri M. Review article: treatment of mild to moderate ulcerative colitis and pouchitis. Aliment Pharmacol Ther 2002;16(Suppl 4):13-19

77 Miglioli M, Barbara L, Di Febo G, et al. Topical administration of 5aminosalicylic acid: a therapeutic proposal for the treatment of pouchitis. N Engl J Med 1989;320(04):257

78 Sambuelli A, Boerr L, Negreira S, et al. Budesonide enema in pouchitis-a double-blind, double-dummy, controlled trial. Aliment Pharmacol Ther 2002;16(01):27-34 
79 de Silva HJ, Ireland A, Kettlewell M, Mortensen N, Jewell DP. Shortchain fatty acid irrigation in severe pouchitis. N Engl J Med 1989; 321(20):1416-1417

80 Wischmeyer P, Pemberton JH, Phillips SF. Chronic pouchitis after ileal pouch-anal anastomosis: responses to butyrate and glutamine suppositories in a pilot study. Mayo Clin Proc 1993;68(10): 978-981
81 Winter TA, Dalton HR, Merrett MN, Campbell A, Jewell DP. Cyclosporin A retention enemas in refractory distal ulcerative colitis and 'pouchitis'. Scand J Gastroenterol 1993;28(08):701-704

82 Gionchetti P, Rizzello F, Venturi A, et al. Oral bacteriotherapy as maintenance treatment in patients with chronic pouchitis: a double-blind, placebo-controlled trial. Gastroenterology 2000; 119(02):305-309 